\title{
Integrated Behavioral Health Care in Viet Nam: Examples from the Hanoi Bach Mai Hospital of Patients with Hypertension
}

\author{
Shiyou Wu ${ }^{1}$, Jennifer Rolfes ${ }^{2}$, Christina M. Clarke ${ }^{2,3}$, Adimika Smith ${ }^{4}$, Do Van Thanh ${ }^{5}$, Bui Minh Thu ${ }^{6}$, \\ Nguyen Thi Huong Giang ${ }^{7}$, Nguyen Thi Lan Anh ${ }^{7,8}$, Pham Thi Thu Huong ${ }^{8,9}$, Pham Thi Thu Hien ${ }^{9}$, \\ Ronald R. ODonnell ${ }^{2}$ **
}

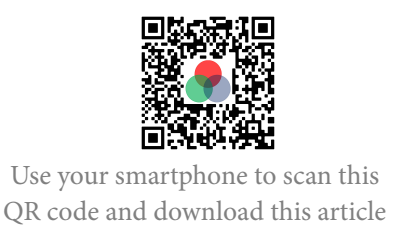

${ }^{1}$ School of Social Work, Arizona State University, AZ, USA

${ }^{2}$ College of Health Solutions, Arizona State University, AZ, USA

${ }^{3}$ Wake Forest School of Medicine, Wake Forest Baptist Health, Winston-Salem, NC, USA

${ }^{4}$ Positive Health Counseling, USA

${ }^{5}$ Bach Mai Hospital, Ha Noi, Viet Nam

${ }^{6}$ Bach Mai Medical College, Bach Mai Hospital, Ha Noi, Viet Nam

${ }^{7}$ Nursing Department, Bach Mai Hospital, Ha Noi, Viet Nam

${ }^{8}$ Faculty of Nursing and Midwifery, Hanoi Medical University, Hanoi, Viet Nam

${ }^{9}$ National Institute of Mental Health, Bach Mai Hospital, Hanoi, Viet Nam

Correspondence

Ronald R. ODonnell, College of Health Solutions, Arizona State University, AZ, USA

Email: Ronald.odonnell@asu.edu

History

- Received: Aug 03, 2021

- Accepted: Jan 08, 2022

- Published: Feb 04, 2022

DOI : 10.15419/ajhs.v8i1.499

\section{Check for updates}

\section{Copyright}

(c) Biomedpress. This is an openaccess article distributed under the terms of the Creative Commons Attribution 4.0 International license.

\begin{abstract}
Objectives: Behavioral conditions contribute to poor clinical outcomes and are not routinely addressed in medical settings in Viet Nam. Few studies focus on the level of integrated care in clinics, the provider ratings of the prevalence of behavioral conditions, the need for a behavioral health consultant (BHC), and patient health risk assessments (HRAs) in Viet Nam. To fill these research gaps, this study aims to explore the level of behavioral health integration in primary care clinics, the provider perceived prevalence of behavioral problems, the need for an expert behavioral health consultant on the primary care team, and the health risks for patients in Viet Nam. Methodology: This study collected first-hand survey data from two healthcare sites, 41 service providers, and 199 patients in Hanoi, Viet Nam. Regression analyses were conducted to examine the relationship between HRA behavioral conditions and each of the biometric health risk factors. Results: The healthcare site and provider survey results showed low levels of integrated health services, provider perceptions of the moderate prevalence of common behavioral conditions, and the need for a BHC to assist in care. In addition, the patient's HRA results showed an elevated risk of sleep apnea, fruit and vegetable intake, tobacco, alcohol use for men, and poor health literacy. Conclusion: The level of integrated care services is low in Viet Nam, the need for the providers to have a $\mathrm{BHC}$ to assist in treatment is moderate, and the patients reported elevated health risks in several areas. The findings demonstrated a pressing need for the development of integrated behavioral health care services in Viet Nam.
\end{abstract}

Key words: Integrated Healthcare, health risk assessment, Hypertension, biometric health risks, Vietnam

\section{INTRODUCTION}

Non-communicable diseases (NCDs) are increasing globally and account for $82 \%$ of NCD-related deaths in low- and middle-income countries ${ }^{1}$. Behavioral health risk factors such as physical inactivity, poor nutrition, tobacco use, and excessive alcohol use are the main causes of many NCD's ${ }^{2}$. Economic transitions in Asia have led to a change from low-calorie, high fiber foods to processed foods that are high in fat, salt, and sugar ${ }^{3,4}$. Changes in the workforce have led to more sedentary time and workplace technological changes contribute to decreasing physical activity levels ${ }^{5-7}$. Integrated behavioral health, the teambased systemic treatment of NCD, lifestyle, and behavioral (psychiatric and substance use disorder) conditions in medical settings such as primary care clinics, is viewed as an urgent need in Asia ${ }^{8}$. Integrated behavioral health interventions are associated with reduced hospital admissions and readmissions, a decreased hospital length of stay, lowered healthcare costs, enhanced adherence to treatment recommendations, and clinical and quality outcomes ${ }^{9,10}$. However, there is no feasible and standardized approach to defining and measuring integrated healthcare in practice ${ }^{11}$, resulting in a lack of consensus among stakeholders on the implementation and funding of integrated care globally ${ }^{12}$.

\section{Hypertension and Type 2 Diabetes in Viet Nam}

Viet Nam is a low to middle-income country that is epidemiologically transitioning from acute care for communicable diseases to non-communicable chronic care ${ }^{13,14}$.This epidemiological transition can be attributed to changes in the population, socio-demographic characteristics, and life expectancies $^{13,14}$. Hypertension has increased from $16.9 \%$ in $2001-2002$ to $25.1 \%$ in 2008 and $33 \%$ in $2009^{14}$. A recent meta-analysis found a pooled prevalence of hypertension of $21.9 \%$ based on research studies and 
$18.4 \%$ based on national surveys. This may be more accurate due to the larger sample size ${ }^{15}$.

\section{Awareness and Treatment}

The patient awareness of having hypertension is $46 \%$ to $48.4 \%$, and only $29.6 \%$ undertook treatment ${ }^{16,17}$.In rural districts, the level of awareness decreases to $17 \%$, and only $6 \%$ undertook treatment ${ }^{18}$. Reasons for lack of awareness and treatment include the inadequate training of community health care workers, ineffective health dialogue, a lack of skills to communicate the diagnosis of hypertension, and poor education on hypertension among the general population ${ }^{18}$. Patient education and advocacy are recommended to increase awareness, treatment, and to encourage behavioral changes to improve the outcomes for hypertension ${ }^{19}$. A study in rural Northern Viet Nam found a $49.8 \%$ adherence to hypertension medication $^{20}$.

\section{Risk Factors}

The risk factors for hypertension in Viet Nam include a sedentary lifestyle, obesity, metabolic syndrome, poor eating habits, family history, undiagnosed hypertension, and a nutrition transition 19,21,22. Hypertension in Viet Nam has substantially increased in part due to the accelerated economic improvements, aging population, changes in diet, and urbanization $^{14,23}$.

Overweight and obesity has increased from $2.3 \%$ in 1993 to $15 \%$ in $2015^{24}$. There is a low level of physical activity, a high consumption of salt, instant noodles, sugar-sweetened beverages, and a low consumption of fruit, vegetables and seafood ${ }^{24}$.

Research has demonstrated that there is a significant association between an increased time spent in green space in urban areas (e.g., parks, gardens) and physical and mental health ${ }^{25}$. The beneficial effects of urban green spaces include improved mental health, reduced cardiovascular morbidity and mortality, obesity, and a higher risk of type 2 diabetes ${ }^{25}$. The underlying causal mechanisms that account for the health benefits of green spaces have been proposed as pathways linking greenspace to improved health including decreased air pollution, air temperature, and noise, increased physical activity, stress reduction, and social cohesion or support ${ }^{25}$.

\section{Co-morbid Psychiatric and Substance Use Disorders and Tobacco}

A study of depression among elderly diabetic patients found that $79.4 \%$ reported depressive symptoms ${ }^{26}$.
The prevalence of serious depression was $28 \%$ for cancer patients ${ }^{27}$. Among chronic hepatitis B patients, $37.5 \%$ experienced symptoms of depression ${ }^{28}$. A study of industrial workers found that $38.6 \%$ reported symptoms of depression ${ }^{29}$, and a study of male casual laborers found that $25 \%$ reported depressive symptoms ${ }^{30}$. A study of the elderly in an urban area found that $66.9 \%$ reported depression ${ }^{31}$, and a study of the elderly in a rural setting showed that $26.4 \%$ were positive for depression ${ }^{32}$. A study of patients in Viet Nam, Cambodia, and Myanmar found that the prevalence for anxiety was $17 \%$ while depression was $39.1 \%^{33}$. Depression was greatest among patients with chronic obstructive pulmonary disease $(62.1 \%)$, kidney disease $(55.5 \%)$, Parkinson's disease (53.7\%), and cardiovascular disease (52.6\%). Anxiety was the greatest among the patients with cancer (7.8\%). A related study of alcohol use in these three countries found that $9.3 \%$ of the population were problem drinkers, and that diagnoses of liver disease, gout, other musculoskeletal conditions, kidney disease, and dyslipidemia were positively associated with problem drinking ${ }^{34}$. Tobacco use prevalence was $20.7 \%$ for current tobacco smokers or smokeless tobacco users and $4.1 \%$ for daily tobacco use and problem drinking.

Alcohol consumption is on a sharp rise in Viet Nam with an increase in alcohol consumption per capita from 2003-2005 from 3.1 liters to 8.3 liters in 2015$2017^{35}$. Alcohol use prevalence was $80.3 \%$ for males and $11.2 \%$ for females aged $24-69$ years old, with $44 \%$ of the males engaged in heavy episodic drinking ${ }^{35}$. The WHO reported that $8.9 \%$ of males and $0.9 \%$ of females have an alcohol use disorder. In addition, 5.9\% of males and $0.1 \%$ of females are alcohol dependent ${ }^{36}$.

\section{Treatment of Hypertension in Viet Nam}

The use of a pharmacological intervention where there is the use of medication to control blood pressure is typically used to treat hypertension in Viet $\mathrm{Nam}^{14}$. However, access to medication is problematic, significantly impacting treatment adherence ${ }^{15}$. The challenges to medication access include fragmentation and inconsistency when prescribing medication between different healthcare facility levels and short prescription time spans between follow-up visits to primary healthcare facilities ${ }^{15}$. Hypertension is poorly managed and treated in Viet Nam ${ }^{14,15,37}$.

\section{Workforce}

Research on hypertension indicates the insufficient training of community health care workers, a lack of knowledge, and the overall impact on the general population ${ }^{18}$. As a result, $70 \%$ of community 
health workers cannot ask the pertinent questions that need to be addressed to the patients with hypertension ${ }^{18}$.Furthermore, the barriers that the literature discusses include access to care, diagnosis, treatment, cost, education and management, a lack of knowledge about certain chronic diseases among the lower-tiered health care workers, and a lack of doctors who specialize in NCD's ${ }^{14,38-40}$.

\section{Integrated Healthcare in Viet Nam}

There is a small body of research on integrated behavioral health in Viet Nam. The government has prioritized depression care in primary healthcare $^{41}$. However, in practice, the responsive activities are limited to referrals and pharmacotherapy only. Access to evidence-based care for depression is still very limited ${ }^{41}$. Barriers to integration include the low level of knowledge of depression treatment among physicians, low resource availability in primary care, limited mental health training, and a primary care system that sets mental health apart from general services $^{41}$. A collaborative care for depression program in primary care based on integrated behavioral health was found to be effective, feasible, and acceptable by providers and patients in improving depression outcomes $^{42}$. A community-based depression management intervention that included psychoeducation and yoga in primary care was found to significantly improve depression ${ }^{43}$. The results of a supported self-management intervention for depression in primary care suggested that there was an improvement of depression symptoms ${ }^{44}$. The significant challenges found to implementation and sustainability included a lack of mental health providers, medical providers overburdened with medical cases, low levels of psychological mindedness among patients, and a lack of recognition of depression as a condition amenable to treatment ${ }^{41}$.

\section{The Present Study}

This review shows that behavioral factors such as poor nutrition, a lack of physical activity, tobacco smoking, alcohol abuse, untreated co-morbid psychiatric disorders, and poor medication adherence largely account for the increase of hypertension in Viet Nam. Screening for behavioral risk factors is poor, and integrated healthcare research is lacking. The current study is designed to address this gap by measuring: 1) the level of behavioral health care integration in hospital and community health centers as measured by the Practice Integration Profile ${ }^{45}$; 2) clinician ratings of the prevalence of common behavioral conditions and perceived need for a BHC in the clinic using a Provider Survey ${ }^{46}$, and 3) a patient self-report health risk assessment (HRA) for patients diagnosed with hypertension in Hanoi, Viet Nam. This study focused on three research questions: a) What is the level of behavioral health integration in primary care clinics in Viet Nam compared to the United States? b) What are the provider's perceived prevalence of behavioral problems and the need for an expert behavioral health consultant on the primary care team? and c) What are the results of a health risk assessment for patients?

\section{METHODS}

\section{Setting}

This research was conducted by a doctoral student who deployed a 3-month study in Hanoi, Viet Nam, supported by the USAID Global Development Research (GDR) Scholar grant program in 2019 in partnership with Bach Mai Hospital in Hanoi. Bach Mai hospital was the only hospital in this study because the USAID GDR Scholar program was only focused on this hospital. However, Bach Mai is representative. It is one of the largest hospitals in Viet Nam, providing medical services for more than 900,000 out-patients and 100,000 in-patients each year. The departments identified within the hospital for the study include the Viet Nam National Heart Institute and Endocrinology department. The subjects included healthcare providers (e.g., physicians and nurses), hospital leaders (e.g., departmental heads), and patients diagnosed with hypertension and/or type 2 diabetes at the hospital. This study was approved by the Bach Mai Institute Review Board, and permission was granted to the Vietnamese and United States authors to use this research data for publication.

\section{Subjects}

The subjects included healthcare providers, hospital leaders, and the patients at Bach Mai Hospital. The providers were physicians and nurses providing care in the hospital. The leaders included the departmental heads from various departments in the hospital who were familiar with the full range of services offered in each departmental setting. The leaders were from the Viet Nam National Heart Institute and the Department of Endocrinology of Bach Mai Hospital. The patients were adults, both male and female, with diagnoses of hypertension and/or type 2 diabetes from these two departments.

\section{Procedures}

The PI's university approved the study's human subject protocols. Trained research assistants (RA) recruited the patients as they checked in for a routine 
medical appointment if an out-patient or by inquiring about their interest from those being seen as inpatients. The RA provided a brief description of the study, completed the consent forms, and then completed the demographic and Health Risk Assessment (HRA) forms. Each patient received a payment of $\$ 3$ USD. The RA later collected the patient's biometric data (blood pressure, blood sugar, and BMI) from their medical record. The RA also contacted staff to complete the PIP (clinic leader) or the Provider Survey (physicians and nurses, or other clinicians). The participants received an incentive payment of $\$ 10$ USD.

\section{Measures}

All measures were translated to Vietnamese and back translated into English. The translations were then reviewed by the Vietnamese team and the USA team. The teams agreed that the items for all measures appeared to be face valid and applicable to the providers and patients in Viet Nam as appropriate. The Practice Integration Profile (PIP) is a 30-item, 6-point Likert scale validated measure of the degree of behavioral health integration in primary care ${ }^{45}$. The Provider Survey is a list of 23 behavioral health problems (e.g., headache, depression) to be rated by the primary care clinicians. The clinician rates the prevalence of each symptom in practice and how often they would request a consultation with a behavioral health clinician ${ }^{46}$.The subscales for mental and behavioral health are reported based on the methodology developed by Wardell ${ }^{47}$. The study's Health Risk Assessment is comprised of the My Own Health Report (MOHR) ${ }^{48}$. The MOHR includes seven domains: nutrition (4 items from Starting the Conversation $)^{49}$, physical activity (2-items from The exercise vital sign ${ }^{50}$, risky alcohol use $(1 \text {-item })^{51}$, smoking/tobacco use (3-items from the Tobacco use screener $)^{52}$, anxiety and depression as measured by the PHQ $-4^{53}$, stress (1-item from the distress thermometer ${ }^{54}$, and sleep (3-items from the BRFSS ${ }^{52}$ ). The MOHR items were selected from among the validated measures by an expert consensus to screen for the most common symptom presentations in primary care ${ }^{48}$.

This study also included the following measures. The medication adherence visual analog scale (VAS) was validated against the prescription medication refills for chronic disease patients ${ }^{55}$. The Somatic Symptom Scale (SSS) is a validated 8-item version of the PHQ-15 designed to measure somatic symptom disorders ${ }^{56}$.The abbreviated PTSD Civilian Checklist is a validated 2-item version of the PTSD Checklist ${ }^{57}$.
A Green Health exposure screen developed by the PI was included based on research that greater exposure to green places (e.g., parks, gardens) is associated with improved cardio-metabolic and psychological health status ${ }^{58}$. The patient cardiometabolic health risk measures included systolic and diastolic blood pressure (SBP; DBP), HbA1c, waist circumference (WC), and BMI.

\section{Data Analysis}

Descriptive statistics were used to analyze the demographics, including the participants' income, education level, healthcare, and support. Chi-square and ANOVA were utilized to determine whether there were any significant differences between sites for the patient HRA physical health, mental health, and substance use subscales. The Provider Survey was analyzed utilizing Chi-Square tests with Monte Carlo simulations ( $\mathrm{n}=10,000$ simulations) in cases where there were cell counts less than five ${ }^{59}$.Formal statistical testing cannot be completed for the PIP because most sites had only one observation. Pearson's correlation analysis was conducted for the patient-reported HRA items. Ordinary least squares Regression analyses were conducted to examine the relationship between HRA behavioral conditions and each of the biometric health risk factors (BMI, SBP, DBP, WC) while controlling for the patient demographic variables. 


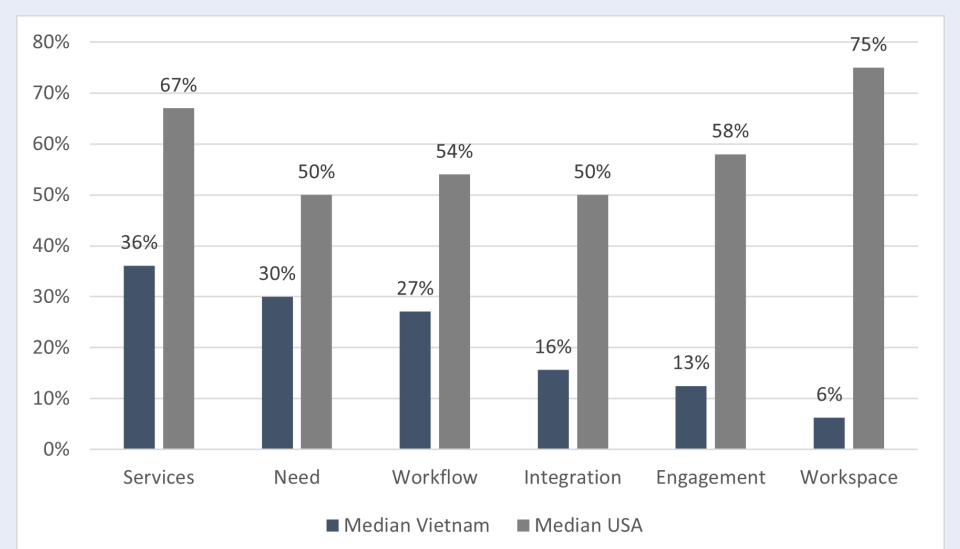

Figure 1: Practice Integration Profile (PIP) Results by Six Domains: Viet Nam vs. USA ( $n=2)$

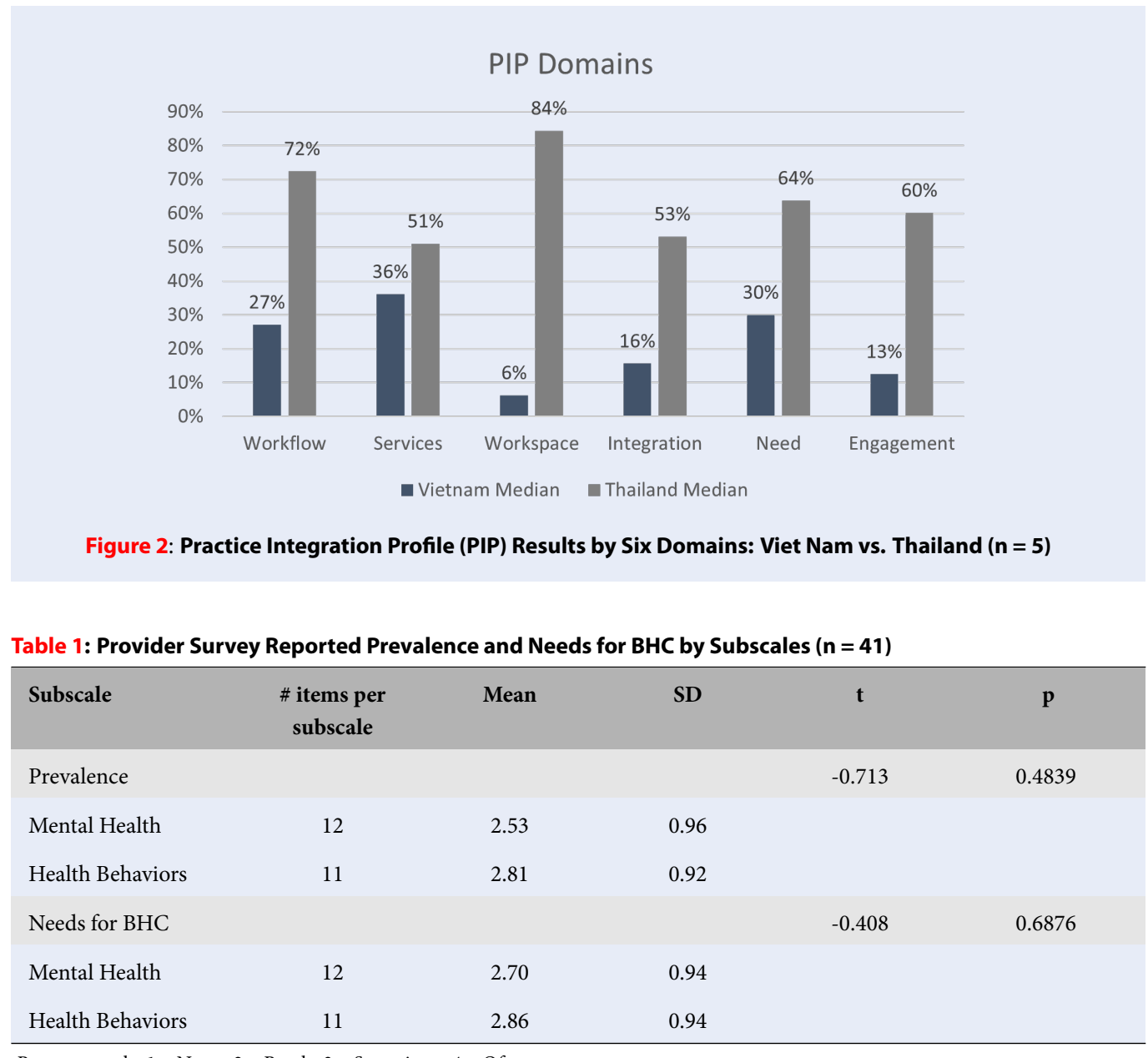

Response scale; $1=$ Never, $2=$ Rarely, $3=$ Sometimes, $4=$ Often 
Table 2: Patient Demographic Statistics ( $N=199)$

\begin{tabular}{|c|c|c|}
\hline & Frequency (n) & Percentage \\
\hline \multicolumn{3}{|l|}{ Gender } \\
\hline Male & 106 & $53 \%$ \\
\hline Female & 93 & $47 \%$ \\
\hline \multicolumn{3}{|l|}{ Age } \\
\hline$<50$ & 30 & $15 \%$ \\
\hline $50-60$ & 40 & $20 \%$ \\
\hline $60-70$ & 73 & $37 \%$ \\
\hline $70+$ & 56 & $28 \%$ \\
\hline \multicolumn{3}{|l|}{ Marital Status } \\
\hline Married & 152 & $76 \%$ \\
\hline Single & 11 & $7 \%$ \\
\hline Widowed & 36 & $18 \%$ \\
\hline \multicolumn{3}{|l|}{ Employment Status } \\
\hline Employed & 64 & $32 \%$ \\
\hline Homemaker & 19 & $10 \%$ \\
\hline Retired & 96 & $48 \%$ \\
\hline Unemployed & 20 & $10 \%$ \\
\hline \multicolumn{3}{|l|}{ Household Number } \\
\hline $1-2$ & 54 & $27 \%$ \\
\hline $3-4$ & 58 & $29 \%$ \\
\hline $5-6$ & 70 & $35 \%$ \\
\hline $7-10$ & 17 & $9 \%$ \\
\hline \multicolumn{3}{|l|}{ Education Status } \\
\hline Less than primary school & 11 & $6 \%$ \\
\hline Primary school graduate & 17 & $9 \%$ \\
\hline Secondary school graduate & 129 & $65 \%$ \\
\hline Some College or higher & 41 & $21 \%$ \\
\hline \multicolumn{3}{|l|}{ Insurance Status } \\
\hline Have insurance & 194 & $97 \%$ \\
\hline No insurance & 5 & $3 \%$ \\
\hline
\end{tabular}


Table 3: Medical Record biometrics and Patient Heath Risk Assessment Descriptive Results $(\mathrm{N}=199)$

\begin{tabular}{|c|c|c|}
\hline \multicolumn{3}{|l|}{ Medical Record Biometrics } \\
\hline \multicolumn{3}{|l|}{ Systolic Blood Pressure (SBP) } \\
\hline Male & 127 & $130-139$ stage 1 \\
\hline Female & 126 & 120-129 elevated \\
\hline \multicolumn{3}{|l|}{ Diastolic Blood Pressure (DBP) } \\
\hline Male & 75 & $<80$ normal \\
\hline Female & 74 & $<80$ normal \\
\hline \multicolumn{3}{|l|}{ BMI } \\
\hline Male & 26 & $23-24.9$ overweight \\
\hline Female & 22 & $>25$ obese \\
\hline \multicolumn{3}{|l|}{ Patient Health Risk Assessment (HRA) } \\
\hline \multicolumn{3}{|l|}{ Physical Health } \\
\hline Sleep Apnea - Snoring (Average) & 0.6 & $60 \%$ Responded Yes \\
\hline Daytime Sleepiness (Weekly Average) & 0.5 & Low Risk on Scale $(0-4)$ \\
\hline Somatic Symptoms (Average) & 7.9 & Low Risk on Scale $(0-32)$ \\
\hline Medication Compliance (\%) & $90 \%$ & \% Compliance \\
\hline Weekly Fast Food (Average Servings) & 0.4 & Low Risk $(<1)$ \\
\hline Daily Fruit and Veggies (Average Servings) & 1.5 & High Risk $(<2)$ \\
\hline Weekly Exercise (Average Minutes) & 176.7 & $>150$ minutes $/$ week $=$ low risk \\
\hline Green Space Days (Weekly Average) & 3.0 & NA \\
\hline Green Space Access (Average) & 8.1 & On a scale of $1-10,10$ highest \\
\hline Green Space Quality (Average) & 7.5 & On a scale of $1-10,10$ highest \\
\hline Comfort with Medical Forms (Average) & 1.5 & Proficient Literacy $(<2)$ on Scale $0-4$ \\
\hline Mental Health & & Risk Level \\
\hline PHQ-4 total & 2.4 & No Risk on Scale $(0-12)$ \\
\hline Stress Level & 4.2 & Medium Risk on Scale $(0-10)$ \\
\hline PTSD & 1.2 & Low Risk on Scale \\
\hline \multicolumn{3}{|l|}{ Substance Use } \\
\hline \multicolumn{3}{|l|}{ Binge Drinking } \\
\hline Male $(\%>1$ day per year) & $7 \%$ & High risk $>1$ day per year \\
\hline Female ( $\%>1$ day per year) & $3 \%$ & \\
\hline \multicolumn{3}{|l|}{ Smoking Cigarettes } \\
\hline Male (\% responding yes) & $13 \%$ & High risk if responding yes \\
\hline Female (\% responding yes) & $10 \%$ & \\
\hline \multicolumn{3}{|l|}{ Chewing Tobacco } \\
\hline Male (\% responding yes) & $3 \%$ & High risk if responding yes \\
\hline Female (\% responding yes) & $3 \%$ & \\
\hline
\end{tabular}


Table 4: Pearson's Correlation among Key Behavioral Conditions Variables

\begin{tabular}{|c|c|c|c|c|c|c|c|c|c|c|c|c|c|c|c|c|c|c|}
\hline & \multicolumn{12}{|c|}{ Physical Health } & \multicolumn{3}{|c|}{ Mental Health } & \multicolumn{3}{|c|}{ "Substance Use } \\
\hline & 1 & 2 & 3 & 4 & 5 & 6 & 7 & 8 & 9 & 10 & 11 & 12 & 13 & 14 & 15 & 16 & 17 & 18 \\
\hline $\begin{array}{l}\text { 1.Sleep } \\
\text { Apnea - } \\
\text { Snoring }\end{array}$ & 1.00 & & & & & & & & & & & & & & & & & \\
\hline $\begin{array}{l}\text { 2.Daytime } \\
\text { Sleepiness }\end{array}$ & 0.11 & 1.00 & & & & & & & & & & & & & & & & \\
\hline $\begin{array}{l}\text { 3.Somatic } \\
\text { Symptoms }\end{array}$ & -0.06 & 0.05 & 1.00 & & & & & & & & & & & & & & & \\
\hline $\begin{array}{l}\text { 4.Medication } \\
\text { Adherence }\end{array}$ & -0.08 & 0.02 & 0.06 & 1.00 & & & & & & & & & & & & & & \\
\hline $\begin{array}{l}\text { 5.Weekly } \\
\text { Fast Food }\end{array}$ & 0.03 & 0.01 & -0.02 & -0.02 & 1.00 & & & & & & & & & & & & & \\
\hline 6.Daily Fruit & -0.06 & 0.04 & 0.11 & 0.10 & -0.06 & 1.00 & & & & & & & & & & & & \\
\hline $\begin{array}{l}\text { 7.Daily } \\
\text { Vegetables }\end{array}$ & -0.07 & -0.01 & -0.04 & 0.00 & -0.08 & $0.20^{*}$ & 1.00 & & & & & & & & & & & \\
\hline $\begin{array}{l}\text { 8.Weekly } \\
\text { Exercise }\end{array}$ & 0.06 & -0.12 & -0.04 & 0.02 & 0.12 & 0.01 & -0.11 & 1.00 & & & & & & & & & & \\
\hline $\begin{array}{l}\text { 9.Green } \\
\text { Space Days }\end{array}$ & $0.16^{*}$ & $-0.22^{*}$ & 0.00 & 0.03 & $0.18^{\star}$ & $-0.19^{*}$ & 0.01 & $0.33^{*}$ & 1.00 & & & & & & & & & \\
\hline $\begin{array}{l}\text { 10.Green } \\
\text { Space Access }\end{array}$ & -0.01 & -0.03 & -0.02 & -0.05 & -0.02 & -0.09 & -0.03 & -0.01 & $0.40^{*}$ & 1.00 & & & & & & & & \\
\hline $\begin{array}{l}\text { 11.Green } \\
\text { Space } \\
\text { Quality }\end{array}$ & 0.02 & -0.10 & -0.03 & 0.06 & 0.05 & -0.04 & 0.01 & $0.19^{\star}$ & $0.49^{\star}$ & $0.53^{*}$ & 1.00 & & & & & & & \\
\hline $\begin{array}{l}\text { 12.Health } \\
\text { Literacy }\end{array}$ & 0.03 & $0.20^{*}$ & 0.05 & -0.06 & 0.07 & 0.10 & 0.00 & -0.11 & $-0.16^{*}$ & 0.04 & -0.07 & 1.00 & & & & & & \\
\hline 13.PHQ-4 & 0.00 & -0.01 & $0.38^{\star}$ & 0.01 & 0.03 & 0.07 & -0.01 & 0.04 & -0.01 & 0.00 & -0.07 & -0.02 & 1.00 & & & & & \\
\hline 14.PTSD & -0.03 & 0.06 & $0.29^{*}$ & -0.13 & -0.02 & 0.08 & -0.02 & 0.04 & -0.06 & 0.07 & -0.04 & 0.04 & $0.386^{*}$ & 1.00 & & & & \\
\hline
\end{tabular}




\begin{tabular}{|c|c|c|c|c|c|c|c|c|c|c|c|c|c|c|c|c|c|}
\hline \multicolumn{18}{|c|}{ Table 4 continued } \\
\hline 15.Stress & -0.02 & -0.06 & $0.36^{*}$ & -0.04 & 0.06 & 0.08 & -0.01 & 0.03 & 0.07 & -0.04 & 0.07 & $0.18^{*}$ & $0.52^{\star}$ & $0.28^{\star}$ & 1.00 & & \\
\hline 16.Binge & -0.05 & -0.03 & -0.10 & 0.05 & 0.02 & 0.03 & 0.04 & $0.20^{*}$ & 0.03 & 0.09 & 0.03 & 0.04 & 0.03 & 0.0 .76 & 0.03 & 1.00 & \\
\hline \multicolumn{18}{|l|}{ Drinking } \\
\hline 17.Smoking & 0.00 & -0.01 & -0.05 & 0.04 & 0.03 & 0.00 & -0.03 & 0.03 & 0.08 & 0.10 & 0.06 & 0.12 & 0.05 & -0.07 & -0.03 & $0.42^{*}$ & 1.00 \\
\hline 18.Smokeless & -0.07 & -0.12 & -0.01 & -0.04 & $0.15^{\star}$ & -0.09 & 0.04 & -0.04 & $0.16^{*}$ & 0.06 & 0.14 & 0.02 & -0.02 & -0.01 & -0.03 & 0.09 & $0.49^{*} \quad 1.00$ \\
\hline Tobacco & & & & & & & & & & & & & & & & & \\
\hline
\end{tabular}


Table 5: Regression Results of HRA Behavioral Conditions on Biometric Health Risk Factors

\begin{tabular}{|c|c|c|c|c|}
\hline Variables & $\begin{array}{c}\text { (1) BMI } \\
\text { Coef. }[95 \% \mathrm{CI}]\end{array}$ & $\begin{array}{l}\text { (2) Systolic BP } \\
\text { Coef. }[95 \% \text { CI] }\end{array}$ & $\begin{array}{l}\text { (3) Diastolic BP } \\
\text { Coef. [95\% CI] }\end{array}$ & $\begin{array}{l}\text { (4) Waist Circum } \\
\text { Coef. }[95 \% \mathrm{CI}]\end{array}$ \\
\hline \multicolumn{5}{|l|}{ Demographic variables } \\
\hline Gender ( $1=$ female; $0=$ male $)$ & $0.64[-0.36-1.62]$ & $-2.61[-7.68-2.45]$ & $-1.32[-4.68-2.03]$ & $-1.86[-5.07-1.36]$ \\
\hline Number of Household residents & $-0.16[-0.42-0.10]$ & $-0.32[-1.65-1.01]$ & $-0.49[-1.38-0.39]$ & $0.56[-0.29-1.41]$ \\
\hline Age & $-0.07^{\star}[-0.12--0.02]$ & $0.22[-0.05-0.48]$ & $-0.09[-0.26-0.09]$ & $-0.16[-0.32-0.01]$ \\
\hline \multicolumn{5}{|l|}{ Marriage status (Ref. $=$ Married) } \\
\hline Single & $2.34[-0.17-4.84]$ & $-9.81[-22.7-3.08]$ & $-5.81[-14.32-2.71]$ & $3.05[-5.10-11.20]$ \\
\hline Widowed & $0.76[-0.58-2.10]$ & $4.97[-2.13-12.07]$ & $3.49[-1.24-8.22]$ & $2.01[-2.52-6.54]$ \\
\hline $\begin{array}{l}\text { Having health insurance }(1=\text { Yes; } \\
0=\text { No })\end{array}$ & $0.81[-3.58-5.20]$ & $-29.95^{\star}[-52.7--7.23]$ & $-19.45^{\star}[-34.44--4.47]$ & $-5.29[-19.63-9.05]$ \\
\hline \multicolumn{5}{|l|}{$\begin{array}{l}\text { Education level (Ref. = High } \\
\text { School) }\end{array}$} \\
\hline Less than primary school & $1.03[-1.00-3.06]$ & $5.32[-5.10-15.73]$ & $-0.25[-7.13-6.62]$ & $3.35[-3.23-9.93]$ \\
\hline Primary school graduate & $-0.20[-2.05-1.66]$ & $2.13[-7.42-11.68]$ & $1.76[-4.56-8.08]$ & $0.72[-5.30-6.75]$ \\
\hline Some college or higher & $-0.59[-1.78-0.61]$ & $-2.75[-8.91-3.42]$ & $-1.09[-5.19-3.02]$ & $1.68[-2.26-5.61]$ \\
\hline \multicolumn{5}{|l|}{$\begin{array}{l}\text { Employment Status (Ref. =Full } \\
\text { Time) }\end{array}$} \\
\hline Homemaker & $1.22[-0.78-3.22]$ & $-3.52[-13.73-6.69]$ & $-0.42[-7.16-6.32]$ & $-0.27[-6.73-6.20]$ \\
\hline Retired & $1.75^{\star}[0.34-3.15]$ & $-1.77[-8.92-5.39]$ & $0.86[-3.89-5.60]$ & $4.91^{\star}[0.38-9.44]$ \\
\hline Unemployed & $-0.19[-2.05-1.66]$ & $7.72[-1.82-19.26]$ & $6.34^{*}[0.04-12.64]$ & $1.49[-4.54-7.52]$ \\
\hline \multicolumn{5}{|l|}{$\begin{array}{l}\text { Patient Health Risk Assessment } \\
\text { (HRA) }\end{array}$} \\
\hline \multicolumn{5}{|l|}{ Physical Health } \\
\hline Sleep Apnea - Snoring & $1.43^{* *}[0.45-2.41]$ & $-1.05[-6.06-3.95]$ & $1.03[-2.30-4.37]$ & $3.27^{\star}[0.08-6.46]$ \\
\hline $\begin{array}{l}\text { Daytime Sleepiness (Weekly Av- } \\
\text { erage) }\end{array}$ & $0.09[-0.30-0.48]$ & $-0.87[-2.90-1.15]$ & $-0.56[-1.91-0.78]$ & $1.27[-0.01-2.55]$ \\
\hline Somatic Symptoms (Average) & $0.02[-0.09-0.14]$ & $0.25[-0.33-0.84]$ & $0.005[-0.38-0.39]$ & $0.24[-0.15-0.62]$ \\
\hline Medication Adherence (\%) & $-0.01[-0.03-0.01]$ & $0.09[-0.01-0.20]$ & $0.025[-0.43-0.09]$ & $-0.02[-0.08-0.05]$ \\
\hline
\end{tabular}




\begin{tabular}{|c|c|c|c|c|}
\hline & & Table 5 continued & & \\
\hline $\begin{array}{l}\text { Weekly Fast Food (Average Serv- } \\
\text { ings) }\end{array}$ & $0.13[-0.72-0.99]$ & $-2.34[-6.92-2.25]$ & $-0.93[-3.96-2.10]$ & $-1.39[-4.30-1.52]$ \\
\hline Daily Fruit (Average Servings) & $0.28[-0.43-1.00]$ & $1.31[-2.40-5.03]$ & $0.09[-2.38-2.55]$ & $-0.74[-3.11-1.63]$ \\
\hline Daily Veggies (Average Servings) & $-0.48[-1.21-0.23]$ & $-1.41[-5.11-2.29]$ & $-0.32[-2.77-2.13]$ & $-3.17^{\star *}[-5.53--0.81]$ \\
\hline Weekly Exercise (in minutes) & $-0.00[-0.002-0.002]$ & $-0.003[-0.01-0.01]$ & $-0.00[-0.01-0.01]$ & $0.003[-0.003-0.01]$ \\
\hline $\begin{array}{l}\text { Green Space Days (Weekly Aver- } \\
\text { age) }\end{array}$ & $0.22^{\star}[0.03-0.41]$ & $0.69[-0.30-1.69]$ & $0.204[-0.46-0.87]$ & $0.19[-0.45-0.82]$ \\
\hline Green Space Access (Average) & $-0.12[-0.31-0.07]$ & $-0.60[-1.59-0.39]$ & $-0.58[-1.24-0.08]$ & $-0.39[-1.03-0.25]$ \\
\hline Green Space Quality (Average) & $-0.12[-0.35-0.11]$ & $0.58[-0.59-1.75]$ & $0.58[-0.19-1.35]$ & $0.30[-0.46-1.74]$ \\
\hline Health literacy (Average) & $0.11[-0.29-0.50]$ & $-0.60[-2.62-1.42]$ & $-0.70[-2.04-0.64]$ & $0.46[-0.83-1.74]$ \\
\hline \multicolumn{5}{|l|}{ Mental Health } \\
\hline PHQ-4 total & $0.08[-0.13-0.28]$ & $0.06[-1.01-1.13]$ & $-0.16[-0.89-0.56]$ & $1.08^{\star *}[0.40-1.76]$ \\
\hline Stress Level & $-0.23^{\star}[-0.44--0.02]$ & $-0.09[-1.17-0.98]$ & $0.77^{\star}[0.06-1.48]$ & $-1.01^{* *}[-1.70-0.32]$ \\
\hline PTSD & $-0.23[-0.49-0.03]$ & $0.89[-1.21-1.39]$ & $0.11[-0.76-0.97]$ & $-0.58[-1.41-0.25]$ \\
\hline \multicolumn{5}{|l|}{ Substance Abuse } \\
\hline Binge Drinking Risk & $0.90[-1.75-3.54]$ & $5.85[-7.78-19.49]$ & $3.80[-5.20-12.80]$ & $2.36[-6.27-10.98]$ \\
\hline Smoking risk & $-2.12^{\star}[-4.04--0.21]$ & $3.24[-6.63-13.12]$ & $1.91[-4.61-8.43]$ & $-5.49[-11.73-0.75]$ \\
\hline Smokless tobacco & $0.10[-3.42-3.62]$ & $18.27^{\star}[0.12-36.43]$ & $10.29[-1.68-22.27]$ & $1.84[-9.61-13.30]$ \\
\hline Constant & $-0.40[-3.92-3.13]$ & $135^{\star * *}[105-165]$ & $97.4^{* * \star}[77.5-117.3]$ & $96.6^{* * *}[77.6-115.6]$ \\
\hline Observations & 177 & 177 & 175 & 174 \\
\hline R-squared & 0.31 & 0.27 & 0.27 & 0.29 \\
\hline
\end{tabular}

Note: $95 \% \mathrm{CI}$ in brackets; ${ }^{* * *} \mathrm{p}<0.001,{ }^{* *} \mathrm{p}<0.01,{ }^{*} \mathrm{p}<0.05$ 


\section{RESULTS}

\section{Level of Integrated Care}

To determine the overview of the integrated care level in Viet Nam, the median of each of the six domains of the PIP survey was reported and compared to the United States. In all of the six domains measured, Bach Mai Hospital scored significantly lower than the median from the United States. The domains Services (36\%), Need (30\%), and Workflow (27\%) were the highest, and Integration (16\%), Engagement (13\%), and Workspace (6\%) were the lowest (see Figure 1). In addition, we compared the PIP median scores for each domain between Viet Nam and the comparable PIP data collected from Thailand ${ }^{60}$ (Figure 2). The Viet Nam scores were all lower than the Thailand scores. One possible reason for this is that Thailand has many community health workers and psychiatric nursing staff working in their clinics, and Viet Nam does not.

Clinician ratings of the prevalence of behavioral conditions and the need for a BHC

The provider survey $(n=41)$ results further showed the prevalence of mental health and health behaviors in Viet Nam and the need for BHC. The results found that the top five conditions that they want behavioral health assistance with are: a) mental health disorders (50\%), b) chronic insomnia (40\%), c) medication non-compliance (40\%), d) chronic and terminal illnesses (40\%), and e) emotional symptoms (31\%). The Provider Survey mean for the prevalence of mental health symptoms was 2.53 and it was 2.81 for health behavior symptoms. The mean reported that the need for a BHC was 2.70 for mental health symptoms and 2.86 for health behavior symptoms on a 4-point Likert scale, indicating a moderate need. The statistical analysis showed there to be no significant differences between the mental health and health behavior subscales (see Table 1).

\section{Patient Demographics and Health Risk As- sessment}

This study also collected data from the patients to present a systematic insight into integrated behavioral health care in Viet Nam. The majority of participants were over 50 years old (85\%), and most were married (76\%). Nearly half of the population was retired, about one-third were fully employed, and $10 \%$ were homemakers. Most participants (65\%) had graduated from high school, with only $21 \%$ having college experience. The average number of persons per household was evenly distributed. Most people had health insurance (97\%), with only $3 \%$ being uninsured (see Table 2).

Table 3 shows the medical record biometrics and patient HRA descriptive results. The biometric data collected from the patient medical record showed elevated systolic and normal diastolic blood pressure for men and women and a mean BMI that falls into the obese category for men but normal weight for women. The results of the HRA for physical health items were mixed. Somatic symptoms and daytime sleepiness were in the low-risk range, but $60 \%$ of patients reported snoring. Physical activity was 176.7 minutes/week, above the target of 150 minutes/week. Weekly fast food fell into low risk, but fruit and vegetable consumption fell into high risk. Medication adherence was high (90\%), and health literacy was poor. The green space ratings showed no risk for the time spent in green places, as well as the good reported access to and quality of the green spaces. The mental health measures showed no risk of depression/anxiety, a low risk of PTSD symptoms, and medium severity for stress. Binge drinking was $7 \%$ for men and $3 \%$ for women, smoking tobacco was $13 \%$ for men and $10 \%$ for women, and chewing tobacco was $3 \%$ for men and women.

\section{Correlations among the Key Behavioral Conditions Variables}

This study further explored the correlations among the key behavioral conditions variables of physical health, mental health, and substance use. The Pearson correlations showed there to be significant positive correlations between physical symptoms and all three mental health items (PHQ-4, PTSD, stress). Poor health literacy was associated with greater daytime sleepiness. Green space days were positively associated with sleep apnea, exercise, smokeless tobacco, and fast food and negatively associated with daytime sleepiness, fruit consumption, and health literacy. Green space quality was positively associated with physical activity. Binge drinking was positively associated with physical activity and tobacco smoking. Smokeless tobacco use was positively associated with fast food intake. Health literacy was positively associated with daytime sleepiness. There were significant positive correlations between most of the green space variables, between the mental health variables, and between smoking and smokeless tobacco (see Table 4).

\section{Relationship Between HRA Behavioral Con- ditions and Biometric Health Risk Factors}

The regression analysis of patient-reported demographic and HRA behavioral condition variables on 
biometric health risks (BMI, SBP, DBP, WC) showed that the significant predictors of age were BMI, having health insurance and SBP and DBP (negative), being retired, and $\mathrm{BMI}$ and $\mathrm{WC}$, and being unemployed and DBP. The HRA variables showed that the significant predictors for sleep apnea were BMI and WC, daily vegetables and WC (negative), green space days and BMI, depression and WC, stress and BMI (negative), $\mathrm{DBP}$ and WC (negative), smoking and BMI (negative), smokeless tobacco and SBP (See Table 5).

\section{DISCUSSIONS AND IMPLICATIONS}

The results of this study are consistent with the study hypotheses, namely that the level of integrated care services is low in Viet Nam compared to the United States, that the perceived need by providers for a Behavioral Health Consultant to assist in treatment is moderate, and that the self-reported HRA shows that patients reported elevated health risks in areas such as fruit and vegetable intake, stress, alcohol, tobacco use, and poor health literacy. The results of the biometrics show an elevated systolic blood pressure for men and BMI in the obese range for men and normal for women. Most of the HRA psychological variables (e.g., depression, anxiety) were not in the highrisk category, which was unexpected. Taken together, the results support the need for integrated behavioral healthcare services in Viet Nam.

The results of the PIP show that the level of behavioral healthcare integration is very low in Viet Nam compared to the United States and Thailand. This is consistent with the research that notes a lack of training in Viet Nam for the large physician and nursing workforce on integrated healthcare and the lack of primary care-based BHC workforces such as social workers or psychologists as has emerged in the United States ${ }^{41}$. The PIP subscales Integration, Engagement, and Workspace appear to reflect the lack of BHC's in primary care to assist physicians and nurses with services such as lifestyle medicine and behavioral interventions for psychiatric and substance use disorders $^{42}$.

The results of the Provider Survey show that physicians and nurses recognize that lifestyle, psychiatric and substance use disorders are common in practice and that there is a need for BHC's to assist in teambased integrated healthcare. These findings indicate that healthcare providers could benefit from formal training in NCD prevention and management and integrated care interventions such as motivational interviewing and nutrition counseling, as well as the development of a new BHC workforce.
The results of the HRA showed that some of the expected lifestyle problems such as daily fruits and vegetables, tobacco use, binge drinking, stress, and snoring were moderate. The low health literacy scores show the need for improved education on hypertension risks and behavioral interventions. It was surprising that the mental health measures of depression, anxiety, and PTSD were in the moderate or lowrisk categories, given the research showing that these problems are significant in Viet $\mathrm{Nam}^{28,32}$. It is possible that the use of the PHQ-4, which is comprised of two items each from the full PHQ-9 for depression and GAD-7 for anxiety, resulted in the loss of sensitivity. The finding that physical symptoms were significantly correlated with the mental health variables is consistent with the research showing that emotional distress is expressed through physical symptoms in Asia ${ }^{61}$. The average number of days spent in green spaces (3) was low, yet satisfaction with access and quality was high. Green space days and quality was associated with less daytime sleepiness and increased physical activity, suggesting that prescribed increased time in green spaces ${ }^{58}$ may be needed in Viet Nam. However, green space days are associated with fast food consumption, smokeless tobacco use, and lower fruit consumption, the opposite of the expected direction $^{58}$.

Medication adherence is very high, consistent with the evidence that medication as a first-line treatment of type 2 diabetes is limited without integrated health treatment for lifestyle and behavioral problems. In addition, the findings that males were obese indicates a need for lifestyle medicine interventions to improve nutrition and physical activity ${ }^{8}$.

Regression diagnostics including residual analysis, multicollinearity tests, the Ramsey test to determine omitted predictors, and the Breusch-Pagan / CookWeisberg test for heteroskedasticity were performed on all multivariate analyses regressions. The only diagnostic test that failed was the test for heteroskedasticity when using waist circumference as the dependent variable. Several transformations were attempted to normalize the data in a way that would correct the non-constant variance without success. There was no commonly seen pattern in the residuals to help the authors determine the appropriate transformation.

The regression results suggest that there are only a couple of consistent drivers based on the small sample size. Insurance status, sleep apnea, being retired, and stress levels were significant predictors in more than one model. The demographic variables age, health 
insurance, being a retiree, or being unemployed predicted greater BMI, SBP, BMI and WC, and DBP, respectively, all consistent with the research on aging and employment on health status ${ }^{2}$. Other significant predictors were sleep apnea for BMI and WC, vegetables and WC (negative), depression, and WC. However, the predictions of green space days with WC (negative) and stress with BMI (negative) were unexpected.

\section{Limitations}

There are several limitations to this study. First, the PIP, Provider Survey, and most HRA screening measures have not been validated in Viet Nam. The PIP and HRA measures have been validated in the US, while the Provider Survey has not. There are no widely used measures of integration or provider ratings on prevalence and the need for behavioral health problems in Viet Nam, and only a few HRA screening measures have been used and validated. A review of the questionnaires with the stakeholders in Viet Nam indicated that all of the measures had good face validity. However, some items on the PIP contained terms that were not familiar to the providers. Second, this study only investigated one hospital with a small sample size, therefore the findings cannot represent other cities of Viet Nam. Another limitation is that this is a descriptive study with one sample of data collected per site. Therefore, this study cannot address changes among physicians and patients over time in a longitudinal study. Lastly, this study was a convenience sample and did not include randomization or a more rigorous research design.

Recommendations for future study include an evaluation of the translation quality and validity, and a look at the reliability of the study measures in each country. A detailed review of the study findings in each country with key stakeholders will be completed in order to identify additional strengths and areas of improvement in this project. A validation study of the PIP in Viet Nam will be completed by this research team. This study will include focus groups of leaders and clinicians to review the measures to identify clear translations versus unclear ones, and what is in need of revision or replacement.

\section{Implications for Behavioral Health}

The PIP leadership survey, clinician Provider Survey, patient self-reported Health Risk Assessment, and medical record biometrics combined provide a complete estimate of the need for integrated behavioral health care in Viet Nam based on the key stakeholders of the leadership, clinicians, and patients. These measures appear to be well-suited for applied research in resource-poor settings that require brief measures that produce actionable data. This study demonstrates the need for integrated behavioral health care in Viet Nam based on the generally low levels of integration.

\section{ABBREVIATIONS}

BHC: Behavioral health consultant, BMI: Body mass index, BRFSS: Behavioral Risk Factor Surveillance System, DBP: diastolic blood pressure, GAD: Generalized anxiety disorder, HbA1c: Hemoglobin A1C, HRA: Health risk assessment, MOHR: My Own Health Report, NCDs: Noncommunicable diseases, PHQ: Patient Health Questionnaire, PIP: Practice Integration Profile, PTSD: Post-traumatic stress disorder, SBP: Systolic blood pressure, SSS: Somatic Symptom Scale, USAID: United States Agency for International Development, VAS: visual analog scale, WC: waist circumference

\section{ACKNOWLEDGMENTS}

None.

\section{AUTHOR'S CONTRIBUTIONS}

S.W., J.R. and R.O. contributed to the conceptualization and design of the study, analysis and interpretation of data. C.C., A.S., T.V.D., T.M.B., T.H.G.N., T.L.A.N., T.T.H.P. and T.T.H.P helped data collection. S.W., J.R. and R.O. were for drafting the article and revising the article critically for important intellectual content. All authors read and approved the final manuscript.

\section{FUNDING}

This work is supported by USAID Global Development Research (GDR) Scholar grant.

\section{AVAILABILITY OF DATA AND MATERIALS}

Data and materials used and/or analyzed during the current study are available from the corresponding author on reasonable request.

\section{ETHICS APPROVAL AND CONSENT TO PARTICIPATE}

This study was conducted in accordance with the amended Declaration of Helsinki. The institutional review board approved the study, and all participants provided written informed consent.

\section{CONSENT FOR PUBLICATION}

Not applicable. 


\section{COMPETING INTERESTS}

The authors declare that they have no competing interests.

\section{REFERENCES}

1. Lozano R, Naghavi M, Foreman K, Lim S, Shibuya K, Aboyans V. Global and regional mortality from 235 causes of death for 20 age groups in 1990 and 2010: a systematic analysis for the Global Burden of Disease Study 2010. Lancet. 2012;380(9859):2095-128. PMID: 23245604. Available from: 10.1016/S0140-6736(12)61728-0.

2. Organization WH. Global status report on noncommunicable diseases 2014. World Health Organization; 2014.

3. Popkin BM. Global nutrition dynamics: the world is shifting rapidly toward a diet linked with noncommunicable diseases. The American Journal of Clinical Nutrition. 2006;84(2):289-98. PMID: 16895874. Available from: 10.1093/ajcn/84.2.289.

4. Steyn NP, McHiza ZJ. Obesity and the nutrition transition in Sub-Saharan Africa. Annals of the New York Academy of Sciences. 2014;1311(1):88-101. PMID: 24725148. Available from: 10.1111/nyas.12433.

5. Goryakin Y, Lobstein T, James WP, Suhrcke M. The impact of economic, political and social globalization on overweight and obesity in the 56 low and middle income countries. Social Science \{\&amp;\}amp; Medicine. 2015;133:67-76. PMID: 25841097. Available from: 10.1016/j.socscimed.2015.03.030.

6. Macniven R, Bauman A, Abouzeid M. A review of populationbased prevalence studies of physical activity in adults in the Asia-Pacific region. BMC Public Health. 2012;12(1):41. PMID: 22251660. Available from: 10.1186/1471-2458-12-41.

7. Ranasinghe $C D$, Ranasinghe P, Jayawardena R, Misra A. Physical activity patterns among South-Asian adults: a systematic review. The International Journal of Behavioral Nutrition and Physical Activity. 2013;10(1):116. PMID: 24119682. Available from: $10.1186 / 1479-5868-10-116$.

8. Tham TY, Tran TL, Prueksaritanond S, Isidro JS, Setia S, Welluppillai V. Integrated health care systems in Asia: an urgent necessity. Clinical Interventions in Aging. 2018;13:2527-38. PMID: 30587945 . Available from: 10.2147/CIA.S185048.

9. Edgren L, Barnard K. Complex adaptive systems for management of integrated care. Leadership in Health Services (Bradford, England). 2012;2725(1):39-51. Available from: 10.1108/ 17511871211198061.

10. Martinez-Gonzalez NA, Berchtold P, Ullman K, Busato A, Egger $M$. Integrated care programmes for adults with chronic conditions: a meta-review. International Journal for Quality in Health Care. 2014;26(5):561-70. PMID: 25108537. Available from: 10.1093/intqhe/mzu071.

11. Bautista MA, Nurjono M, Lim YW, Dessers E, Vrijhoef HJ. Instruments measuring integrated care: a systematic review of measurement properties. The Milbank Quarterly. 2016;94(4):862917. PMID: 27995711. Available from: 10.1111/1468-0009. 12233.

12. Stadnick NA, Sadler E, Sandall J, Turienzo CF, Bennett IM Borkan J. Comparative case studies in integrated care implementation from across the globe: a quest for action. BMC Health Services Research. 2019;19(1):899. PMID: 31775740. Available from: 10.1186/s12913-019-4661-5.

13. Ha DA, Goldberg RJ, Allison JJ, Chu TH, Nguyen HL. Prevalence, awareness, treatment, and control of high blood pressure: a population-based survey in Thai Nguyen, Vietnam. PLoS One. 2013;8(6):e66792. PMID: 23826134. Available from: 10.1371/ journal.pone.0066792.
14. Hien HA, Tam NM, Tam V, Derese A, Devroey D. Prevalence, awareness, treatment, and control of hypertension and its risk factors in (Central) Vietnam. International Journal of Hypertension. 2018;2018:6326984. PMID: 29887994. Available from: $10.1155 / 2018 / 6326984$

15. Meiqari L, Essink D, Wright $P$, Scheele F. Prevalence of hypertension in Vietnam: a systematic review and meta-analysis. Asia-Pacific Journal of Public Health. 2019;31(2):101-12. PMID: 30678477. Available from: 10.1177/1010539518824810.

16. Ha NT, Duy HT, Le NH, Khanal V, Moorin R. Quality of life among people living with hypertension in a rural Vietnam community. BMC Public Health. 2014;14(1):833. PMID: 25113528. Available from: 10.1186/1471-2458-14-833.

17. Son PT, Quang NN, Viet NL, Khai PG, Wall S, Weinehall L. Prevalence, awareness, treatment and control of hypertension in Vietnam-results from a national survey. Journal of Human Hypertension. 2012;26(4):268-80. PMID: 21368775. Available from: 10.1038/jhh.2011.18.

18. Allison JJ, Nguyen HL, Ha DA, Chiriboga G, Ly HN, Tran HT. Culturally adaptive storytelling method to improve hypertension control in Vietnam - "We talk about our hypertension": study protocol for a feasibility cluster-randomized controlled trial. Trials. 2016;17(1):26. PMID: 26762128. Available from: 10.1186/s13063-015-1147-6.

19. Miyakawa M, Shimizu T, Dat NV, Thanh P, Thuy PT, Anh NT. Prevalence, perception and factors associated with diabetes mellitus among the adult population in central Vietnam: a population-based, cross-sectional seroepidemiological survey. BMC Public Health. 2017;17(1):298. PMID: 28381223. Available from: 10.1186/s12889-017-4208-9.

20. Nguyen TP, Schuiling-Veninga CC, Nguyen TB, Vu TH, Wright EP, Postma MJ. Adherence to hypertension medication: quantitative and qualitative investigations in a rural Northern Vietnamese community. PLoS One. 2017;12(2):e0171203. PMID: 28146584. Available from: 10.1371/journal.pone.0171203.

21. Nguyen TP, Nguyen TB, Nguyen TT, Hac VV, Le HH, SchuilingVeninga $C$, et al. Direct costs of hypertensive patients admitted to hospital in Vietnam- a bottom-up micro-costing analysis. BMC Health Serv Res. 2014;14:514. PMID: 25348043. Available from: 10.1186/s12913-014-0514-4.

22. Ta MT, Nguyen KT, Nguyen ND, Campbell LV, Nguyen TV. Identification of undiagnosed type 2 diabetes by systolic blood pressure and waist-to-hip ratio. Diabetologia. 2010;53(10):2139-46. PMID: 20596691. Available from: 10. 1007/s00125-010-1841-6.

23. Meiqari L, Nguyen TP, Essink $D$, Zweekhorst $M$, Wright $P$, Scheele $F$. Access to hypertension care and services in primary health-care settings in Vietnam: a systematic narrative review of existing literature. Global Health Action. 2019;12(1):1610253. PMID: 31120345. Available from: 10 . 1080/16549716.2019.1610253.

24. Chu DT, Nguyet NTM, Dinh TC, Lien NVT, Nguyen KH, Ngoc VTN. An update on physical health and economic consequences of overweight and obesity. Diabetes \{\&amp; \}amp; Metabolic Syndrome. 2018;12(6):1095-100. PMID: 29799416. Available from: 10.1016/j.dsx.2018.05.004.

25. Organization WH. Urban green spaces and health: a review of evidence. Geneva, Switzerland: World Health Organization; 2016.

26. Vu HT, Nguyen TX, Nguyen HT, Le TA, Nguyen TN, Nguyen AT. Depressive symptoms among elderly diabetic patients in Vietnam. Diabetes, Metabolic Syndrome and Obesity. 2018;11:659-65. PMID: 30425543. Available from: 10.2147/ DMSO.S179071.

27. Yen NT, Weiss B, Trung LT. Caseness rates and risk factors for depression among Vietnamese cancer patients. Asian Journal of Psychiatry. 2016;23:95-8. PMID: 27969088. Available from: 10.1016/j.ajp.2016.07.020. 
28. Vu TT, Le TV, Dang AK, Nguyen LH, Nguyen BC, Tran BX. Socioeconomic vulnerability to depressive symptoms in patients with chronic hepatitis B. International Journal of Environmental Research and Public Health. 2019;16(2):255. PMID: 30658423. Available from: 10.3390/ijerph16020255.

29. Tran BX, Vu GT, Pham KT, Vuong QH, Ho MT, Vuong TT. Depressive Symptoms among industrial workers in vietnam and correlated factors: A multi-site survey. International Journal of Environmental Research and Public Health. 2019;16(9):1642. PMID: 31083499. Available from: 10.3390/ijerph16091642.

30. Huy NV, Dunne MP, Debattista J. Factors associated with depression among male casual laborers in urban Vietnam. Community Mental Health Journal. 2015;51(5):575-84. PMID: 25652042. Available from: 10.1007/s10597-015-9835-y.

31. Dao A, Nguyen VT, Nguyen HV, Nguyen LT. Factors associated with depression among the elderly living in urban Vietnam. BioMed Research International. 2018;2018:2370284. PMID: 30596085. Available from: 10.1155/2018/2370284.

32. Vu HT, Lin V, Pham T, Pham TL, Nguyen AT, Nguyen HT. Determining risk for depression among older people residing in Vietnamese rural settings. International Journal of Environmental Research and Public Health. 2019;16(15):2654. PMID: 31349566. Available from: 10.3390/ijerph16152654.

33. Peltzer K, Pengpid S. Anxiety and depressive features in chronic disease patients in Cambodia, Myanmar and Vietnam. South African Journal of Psychiatry. 2016;22(1):940. PMID: 30263167. Available from: 10.4102/sajpsychiatry.v22i1.940.

34. Peltzer K, Pengpid S. Tobacco and alcohol use among chronic disease patients in Cambodia, Myanmar and Vietnam. The Southeast Asian Journal of Tropical Medicine and Public Health. 2016;47(3):536-45. PMID: 27405138.

35. Hanh HT, Assanangkornchai S, Geater AF, Hanh VT. Socioeconomic inequalities in alcohol use and some related consequences from a household perspective in Vietnam. Drug and Alcohol Review. 2019;38(3):274-83. PMID: 30790381. Available from: 10.1111/dar.12909.

36. Luu BN, Nguyen TT, Newman IM. Traditional alcohol production and use in three provinces in Vietnam: an ethnographic exploration of health benefits and risks. BMC Public Health. 2014;14(1):731. PMID: 25037953. Available from: 10.1186/1471-2458-14-731.

37. Son PT, Quang NN, Viet NL, Khai PG, Wall S, Weinehall L. Prevalence, awareness, treatment and control of hypertension in Vietnam-results from a national survey. Journal of Human Hypertension. 2012;26(4):268-80. PMID: 21368775. Available from: 10.1038/jhh.2011.18.

38. Baumann LC, Blobner D, Binh TV, Lan PT. A training program for diabetes care in Vietnam. The Diabetes Educator. 2006;32(2):189-94. PMID: 16554421. Available from: 10.1177/ 0145721706286569.

39. Beran D, Higuchi M. Delivering diabetes care in the Philippines and Vietnam: policy and practice issues. Asia-Pacific Journal of Public Health. 2013;25(1):92-101. PMID: 21727084. Available from: 10.1177/1010539511412177.

40. Beran D, Yudkin JS. Looking beyond the issue of access to insulin: what is needed for proper diabetes care in resource poor settings. Diabetes Research and Clinical Practice. 2010;88(3):217-21. PMID: 20447710. Available from: 10.1016/j.diabres.2010.03.029.

41. Murphy J, Goldner E, Corbett KK, Morrow M, Nguyen VC, Linh DT, et al. Conceptualizing depression in Vietnam: primary health care providers single explanatory models of depression. Transcultural Psychiatry. 2018;55(2):219-41. PMID: 29405843. Available from: 10.1177/1363461517748846.

42. Ngo VK, Weiss B, Lam T, Dang T, Nguyen T, Nguyen MH. The Vietnam multicomponent collaborative care for depression program: development of depression care for low-and middle-income nations. Journal of Cognitive Psychotherapy. 2014;28(3):156-67. PMID: 25568593. Available from: 10.1891/0889-8391.28.3.156.

43. Niemi M, Kiel S, Allebeck P, Hoan T. Community-based intervention for depression management at the primary care level in Ha Nam Province, Vietnam: a cluster-randomised controlled trial. Tropical Medicine \& International Health. 2016;21(5):654-61. PMID: 26821247. Available from: 10.1111/ tmi.12674.

44. Murphy JK, Xie H, Nguyen VC, Chau LW, Oanh PT, Nhu TK. Is supported self-management for depression effective for adults in community-based settings in Vietnam?: a modified stepped-wedge cluster randomized controlled trial. International Journal of Mental Health Systems. 2020;14(1):8. PMID: 32071614. Available from: 10.1186/s13033-020-00342-1.

45. Kessler RS, Auxier A, Hitt JR, Macchi CR, Mullin D, van Eeghen $C$, et al. Development and validation of a measure of primary care behavioral health integration. Families, Systems \& Health. 2016;34(4):342-56. PMID: 27736110. Available from: 10.1037/ fsh0000227.

46. Hunter CL, Goodie JL, Oordt MS, Dobmeyer AC. Integrated behavioral health in primary care: Step-by-step guidance for assessment and intervention. American Psychological Association; 2009.

47. Wardell B. Integrated Care: Degree of Integration and Perceived Need for Behavioral Health Combined with Primary Care. (Unpublished doctoral culminating project). Arizona State University, Tempe, Arizona. 2017.; 2019.

48. Glasgow RE, Kessler RS, Ory MG, Roby D, Gorin SS, Krist A. Conducting rapid, relevant research: lessons learned from the My Own Health Report project. American Journal of Preventive Medicine. 2014;47(2):212-9. PMID: 24953520. Available from: 10.1016/j.amepre.2014.03.007.

49. Paxton AE, Strycker LA, Toobert DJ, Ammerman AS, Glasgow RE. Starting the conversation performance of a brief dietary assessment and intervention tool for health professionals. American Journal of Preventive Medicine. 2011;40(1):6771. PMID: 21146770 . Available from: 10.1016/j.amepre.2010. 10.009 .

50. Sallis R. Developing healthcare systems to support exercise: exercise as the fifth vital sign. British Journal of Sports Medicine. 2011;45(6):473-4. PMID: 21292925. Available from: 10.1136/bjsm.2010.083469.

51. Smith PC, Schmidt SM, Allensworth-Davies D, Saitz R. Primary care validation of a single-question alcohol screening test. Journal of General Internal Medicine. 2009;24(7):783-8. PMID: 19247718. Available from: 10.1007/s11606-009-0928-6.

52. Centers for Disease Control and Prevention. Behavioral risk factor Surveillance system (BRFSS) Questionnaire. Available online at https://www.cdc.gov/brfss/questionnaires/pdf-que s/2009brfss.pdf. Accessed on November 25, 2020.

53. Kroenke K, Spitzer RL, Williams JB, Lowe B. An ultra-brief screening scale for anxiety and depression: the PHQ-4. Psychosomatics. 2009;50(6):613-21. PMID: 19996233.

54. Roth AJ, Kornblith AB, Batel-Copel L, Peabody E, Scher HI, Holland JC. Rapid screening for psychologic distress in men with prostate carcinoma: a pilot study. Cancer. 1998;82(10):19048. PMID: 9587123 . Available from: 10.1002/(SICI)10970142(19980515)82:10<1904::AID-CNCR13>3.0.CO;2-X.

55. Nau DP, Steinke DT, Williams LK, Austin R, Lafata JE, Divine $G$. Adherence analysis using visual analog scale versus claims-based estimation. The Annals of Pharmacotherapy. 2007;41(11):1792-7. PMID: 17925497. Available from: 10.1345/aph.1K264.

56. Toussaint A, Lowe B, Brahler E, Jordan P. The Somatic Symptom Disorder-B Criteria Scale (SSD-12): factorial structure, validity and population-based norms. Journal of Psychosomatic Research. 2017;97:9-17. PMID: 28606504. Available from: 10.1016/j.jpsychores.2017.03.017.

57. Lang AJ, Stein MB. An abbreviated PTSD checklist for use as a screening instrument in primary care. Behaviour Research and Therapy. 2005;43(5):585-94. PMID: 15865914. Available from: $10.1016 /$ j.brat.2004.04.005.

58. O'Donnell R. Green and blue wellness: A new model of improving physical and mental health. Journal of Nursing and Health Sciences. 2017;3(1):18-25. Available from: 
https://www.rroij.com/open-access/green-and-blue-wellnessa-model-for-improving-physical-and-mental-health-php? aid $=85548$.

59. Bradley DR, Cutcomb S. Monte Carlo simulations and the chisquare test of independence. Behavior Research Methods and Instrumentation. 1977;9(2):193-201. Available from: 10.3758/ BF03214499.
60. O'Donnell R, Wu S, Rolfes J, Tungpunkom P, Tamdee D, Turtle $E$, et al. Integrated behavioral healthcare in Thailand: A case study from Chiang Mai. Psychosomatic Medicine Research. In press.

61. Grover S, Ghosh A. Somatic symptom and related disorders in Asians and Asian Americans. Asian Journal of Psychiatry. 2014;7(1):77-9. PMID: 24524716. Available from: 10.1016/j. ajp.2013.11.014. 
Ready to submit your manuscript? Choose Biomedpress and benefit from:

- Fast, convenient online submission

- Through peer-review by experienced researchers

- Rapid publication on acceptance

- Free of charge (without publication fees)

Learn more http://www.biomedpress.org/journals/
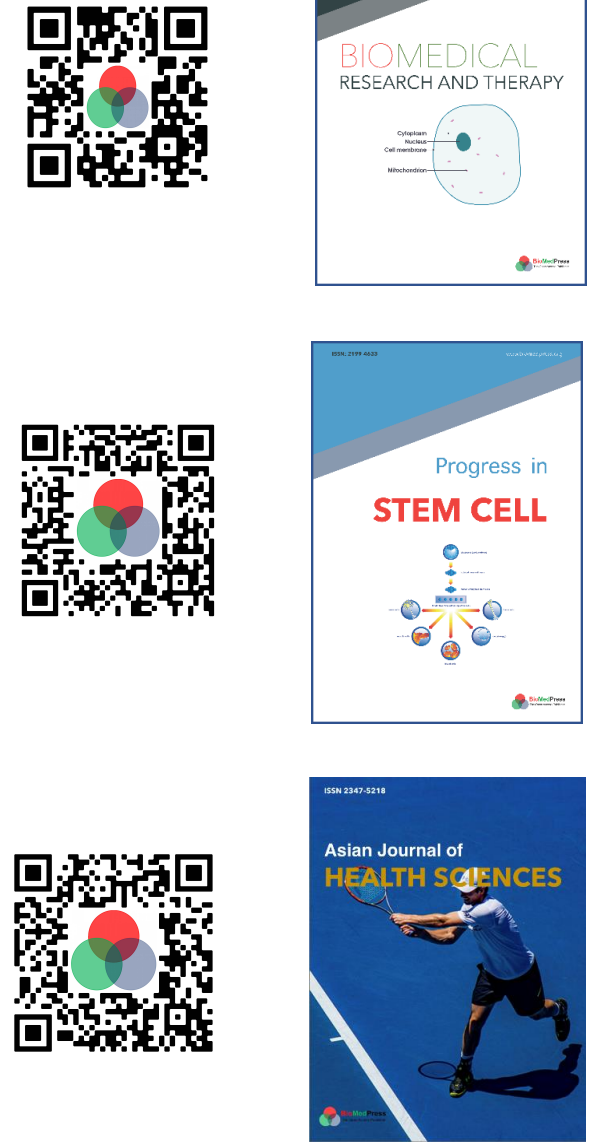

Asian Journal of Health Sciences

ISSN: 2347-5218

Indexed: Google Scholar

Acceptance Rate (2020): 72.89\%

Article Publishing Charge: Free

Submission to first editorial decision: 16.5 days

Biotechnological Research

ISSN: 2395-6763

Indexed: Google Scholar

Acceptance Rate (2020): $67.02 \%$

Article Publishing Charge: Free

Submission to first editorial decision: 28.5 days 